\title{
三峡库区消落带土壤有机质和全氮含量分布特征
}

\author{
郭劲松 ${ }^{1}$, 黄轩民 ${ }^{1}$, 张 柆 $^{1,2}$, 方 芳 ${ }^{1}$, 付 川 $^{3}$ \\ (1: 重庆大学城市建设与环境工程学院,重庆 400045) \\ (2: 西华大学能源与环境学院,成都 610039) \\ (3: 重庆三峡学院化学与环境工程学院,重庆 404000)
}

摘 要: 在三峡库区消落带落干期间 (2010 年 4 月), 对库区巫山-重庆主城区段消落带土壤有机质 (OM) 和全氮 ( TN) 含 量分布及与土壤理化性质的相关性进行了调查研究. 结果表明该区域消落带土壤 OM 和 TN 含量均较低, 分别为 $10.70 \pm$ 4.03 和 $0.84 \pm 0.39 \mathrm{mg} / \mathrm{g}$, 且服从正态分布. 消落带土壤碳氮比 $(\mathrm{C} / \mathrm{N})$ 较低, 推测消落带土壤无机氮在淹水期间存在向上 覆水体释放的可能性. 在与其它关于土壤 $\mathrm{OM}$ 和 TN 含量研究的比较中, 研究区域内土壤 OM 和 TN 含量处于偏低的水平; 而在与对照带样品的比较分析中发现, 消落带样品的 $\mathrm{OM}$ 和 $\mathrm{TN}$ 含量变异系数均偏低, 因此消落带干湿交替可减小不同 区域消落带之间土壤 OM 和 TN 含量差异. 相关性分析表明, 消落带土壤 $\mathrm{pH} 、 \mathrm{ORP} 、 \mathrm{TN}$ 与 OM 之间呈显著正相关, 可见研 究范围内消落带土壤氮形态可能主要以有机氮的形式存在于有机质中, 而 $\mathrm{C} / \mathrm{N}$ 与 $\mathrm{TN}$ 呈负相关, 与 $\mathrm{OM}$ 相关性不显著, 表 明 $\mathrm{C} / \mathrm{N}$ 的大小主要取决于 TN 含量.

关键词: 消落带;土壤;有机质;全氮;三峡库区

\section{Distribution characteristics of organic matter and total nitrogen in the soils of water-level- fluctuating zone of Three Gorges Reservoir area}

\author{
GUO Jinsong ${ }^{1}$, HUANG Xuanmin ${ }^{1}$, ZHANG Bin ${ }^{1,2}$, FANG Fang ${ }^{1} \&$ FU Chuan ${ }^{3}$ \\ (1: Faculty of Urban Construction and Environmental Engineering, Chongqing University, Chongqing 400045, P. R. China) \\ (2: Energy and Environment College of Xihua University, Chengdu 610039, P. R. China) \\ (3: Faculty of Chemistry and Environmental Engineering, Chongqing Three Gorges University, Chongqing 404000, P. R. China)
}

\begin{abstract}
The distribution characteristics of organic matter( OM) and total nitrogen(TN) in the soils of water-level-fluctuating zone( WLFZ) of Three Gorges Reservoir were studied during the non-flooded period, while the correlation among the soil physicalchemical characteristics, OM and TN contents was also be analyzed. OM and TN contents in the soils of WLFZ were both fairly low, were $10.70 \pm 4.03$ and $0.84 \pm 0.39 \mathrm{mg} / \mathrm{g}$, respectively; however, they followed the normal distribution. The lower $\mathrm{C} / \mathrm{N}$ ratio of the soils of WLFZ suggested possibility of releasing of inorganic nitrogen from soil in the WLFZ to overlying water in the flood period. Compared with other study areas, the OM and TN contents were at the low level. The variation coefficients of OM and TN contents of the soil samples of WLFZ were on the low side by comparison with those in control zone. That is why the differences of $\mathrm{OM}$ and TN contents among difference WLFZ of study areas could be reduced by cyclic drying and wetting of WLFZ periodically. Correlation analysis showed that $\mathrm{pH}$, oxidation-reduction potential( ORP), TN was significantly and positively correlated with OM. The result indicated that organic nitrogen was the main nitrogen compositions in soils of WLFZ of the study area. Soil C/ $\mathrm{N}$ ratio was negatively correlated with $\mathrm{TN}$, but insignificantly correlated with $\mathrm{OM}$, suggesting that soil $\mathrm{C} / \mathrm{N}$ ratio was mainly determined by the content of TN.
\end{abstract}

Keywords: Water-level-fluctuating zone; soil; organic matter; total nitrogen; Three Gorges Reservoir area

消落带是指江河、湖泊、水库等水体水位因季节性涨落使土地被周期性淹没和出露成陆形成的干湿交

* 国家水体污染控制与治理科技重大专项项目(2009ZX07104-003,2009ZX07104-002)资助. 2011-10-25 收稿;2011 - 12-05 收修改稿. 郭劲松, 男,1963 年生, 教授; E-mail：guo0768@126. com. 
替的水陆衔接地带 ${ }^{[1]}$. 消落带可以看作淡水湿地的一种, 属于一类特殊的湿地生态系统 ${ }^{[2-3]}$, 具有敏感而脆 弱的生态环境, 在淹水期间易与上覆水发生物质交换和能量传递. 三峡库区消落带的垂直距离为 $30 \mathrm{~m}$ (水 位 $145 \sim 175 \mathrm{~m}$ )、面积为 $348.93 \mathrm{~km}^{2}$. 同时, 随着水位变化, 三峡库区消落带每年有大量土地处于季节性淹没 状态和非淹没状态, 此时其干湿交替的环境条件以及附近居民的耕作等因素都可能对三峡库区消落带的土 壤生态环境及水环境产生各种影响.

有机质( Organic Matter, OM) 和全氮 (Total Nitrogen, TN) 是湿地土壤重要的组成部分, 也是湿地生态系 统十分重要的生态因子, 其含量变化对湿地生态系统的生产力影响非常显著 ${ }^{[4]}$. OM 含量是土壤肥力状况的 重要指标, 并为水体及土壤中的生物活动提供了能源和基质, 在维持生物多样性方面起着至关重要的作 用 ${ }^{[5-6]}$. 氮素则是湿地生态系统中最重要的限制因素之一, 也是水体发生富营养化的重要诱导因子, 是一种 湿地营养水平指示物 ${ }^{[7]}$, 而消落带是淡水湿地的一种, 具有类似湿地的生态环境特征. 目前, 有关三峡库区 消落带土壤的研究主要集中在重金属含量调查 ${ }^{[8]}$ 、氮磷形态分布特征 ${ }^{[9-11]}$ 和氮磷吸附释放规律 ${ }^{[12-13]}$ 等方面, 而关于三峡库区消落带在经历多次反复的淹水一出露后, 消落带土壤 OM 和 TN 含量特征的研究较少.

本文针对三峡库区巫山一重庆主城区段消落带,于 2010 年 4 月对该区域土壤 $\mathrm{OM}$ 和 TN 含量进行研究, 分析了二者在研究区域中的分布规律和土壤理化特征, 及 $\mathrm{OM} 、 \mathrm{TN}$ 和 $\mathrm{C} / \mathrm{N}$ 三者的相互联系及土壤中碳、氮的 转化, 以期为三峡库区消落带土壤 $\mathrm{OM}$ 、TN 含量变化和碳氮物质循环提供基础数据与科学依据.

\section{1 材料与方法}

\section{1 研究区域}

三峡库区巫山一重庆主城区段消落带 $\left(28^{\circ} 28^{\prime} \sim 31^{\circ} 44^{\prime} \mathrm{N}, 105^{\circ} 49^{\prime} \sim 110^{\circ} 12^{\prime} \mathrm{E}\right)$ 面积约为 $306.28 \mathrm{~km}^{2}$, 总 共涉及 22 个区县 (市), 遍布于长江干流和库区大大小小百余条次级河流. 库区地貌类型复杂多样, 以山地 为主. 研究区域地处亚热带季风气候区, 具有雨热同季、热量丰富、雨量充沛、空气潮湿、云雾较多等气候特 点, 多年年均温度 $18.1^{\circ} \mathrm{C}$, 最热月均温度 $28.4^{\circ} \mathrm{C}$, 最冷月均温度 $7^{\circ} \mathrm{C}$, 是全国著名的高温区. 年降雨量 $1087 \sim$ $1400 \mathrm{~mm}$,但季节分配不均,降雨集中在夏季,相对湿度 $79 \%$ 82\% ${ }^{[14]}$.

\section{2 样品采集与分析}

在研究区域内共选择了 14 个采样点 (图 1), 贯穿整个三峡库区重庆段消落带, 分布于长江干流以及干 流南北两侧重要的支流消落带; 除此之外, 在消落带面积较大的区县, 不同土地利用方式和类型的消落带均 分布有采样点, 具体信息详见表 1 , 共采集样品 54 个. 采样期间 (2010 年 4 月) 的水位为 $154 \mathrm{~m}$, 所采集的样品

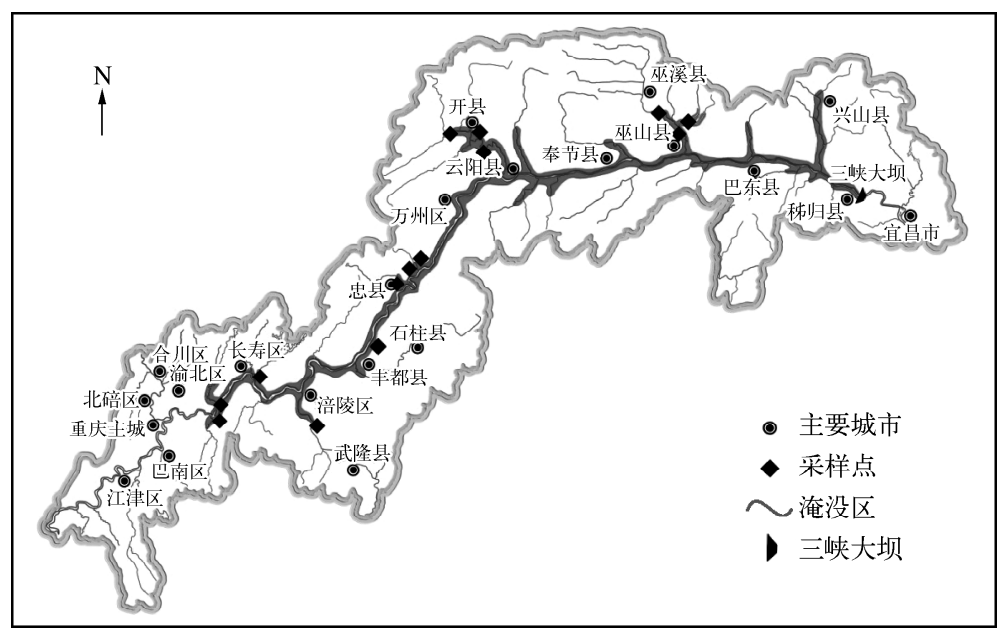

图 1 三峡库区消落带采样点分布图

Fig. 1 Distribution of sampling sites of water-level-fluctuating zone in

Three Gorges Reservoir area 
分为两部分: 1) 刚出露的消落带土壤样品 (样品数 $n=41$ ), 淹水历时约 7 个月, 每个采样点按 $154 \sim 175 \mathrm{~m}$ 的 高程区间均匀分成上、中、下 3 个区段分别采集 1 份土壤样品, 其中, 忠县新政村未能采集到下部的土壤样 品; 2) 对照带土壤样品 (样品数 $n=13$ ), 未被库区水体淹没过, 在高程 $175 \sim 180 \mathrm{~m}$ 之间采集 1 份土壤样品, 其中, 开县汉丰湖未能采集到土壤样品. 采集土样时, 使用洛阳铲采集表层土 $(0 \sim 20 \mathrm{~cm})$, 为了使所采样品 具有代表性, 在 $1 \mathrm{~m}$ 范围内采集 $4 \sim 5$ 个不同土样, 捡掉砾石、动植物残体等, 充分混合后用四分法缩分至 $1 \mathrm{~kg}$ 左右, 装人聚乙烯袋密封保存带回实验室. 样品采集时同时测定各采样点的经纬度、酸碱度 $(\mathrm{pH})$ 、氧化 还原电位 $(\mathrm{ORP})$ 和含水率.

\section{表 1 采样点位置}

Tab. 1 The location of sampling sites

\begin{tabular}{|c|c|c|c|}
\hline 采样点名称 & 所在流域 & 地理坐标 & 淹没前土地利用状况 \\
\hline 忠县共和村 & 长江 & $30^{\circ} 24^{\prime} \mathrm{N}, 108^{\circ} 08^{\prime} \mathrm{E}$ & $\begin{array}{l}\text { 某研究单位示范基地, 主要种植了 } \\
\text { 牛鞭草, 狗牙根等植物 }\end{array}$ \\
\hline 忠县新政村 & 长江 & $30^{\circ} 25^{\prime} \mathrm{N}, 108^{\circ} 10^{\prime} \mathrm{E}$ & 农业用地 ～～～～～～～ \\
\hline 丰都县汶溪村 & 长江 & $29^{\circ} 59^{\prime} \mathrm{N}, 107^{\circ} 50^{\prime} \mathrm{E}$ & 农业用地 \\
\hline 南岸区广阳坝干流 & 长江 & $29^{\circ} 35^{\prime} \mathrm{N}, 106^{\circ} 43^{\prime} \mathrm{E}$ & 河滩地 \\
\hline 巫山县周家湾 & 大宁河 & $31^{\circ} 18^{\prime} \mathrm{N}, 109^{\circ} 46^{\prime} \mathrm{E}$ & 农业用地 ～～～ \\
\hline 巫山县大昌古镇 & 大宁河 & $31^{\circ} 16^{\prime} \mathrm{N}, 109^{\circ} 47^{\prime} \mathrm{E}$ & 大昌古镇遗址所在地 \\
\hline 巫山县洋溪河河口 & 大宁河 & $31^{\circ} 17^{\prime} \mathrm{N}, 109^{\circ} 50^{\prime} \mathrm{E}$ & 农业用地 \\
\hline 开县汉丰湖 & 澎溪河 & $31^{\circ} 11^{\prime} \mathrm{N}, 108^{\circ} 26^{\prime} \mathrm{E}$ & 开县县城遗址所在地 \\
\hline 开县白家溪 & 澎溪河 & $31^{\circ} 09^{\prime} \mathrm{N}, 108^{\circ} 34^{\prime} \mathrm{E}$ & 农林用地 \\
\hline 云阳县养鹿湖 & 澎溪河 & $31^{\circ} 05^{\prime} \mathrm{N}, 108^{\circ} 34^{\prime} \mathrm{E}$ & 农林用地 \\
\hline 忠县新桥村 & 甘井河 & $30^{\circ} 19^{\prime} \mathrm{N}, 108^{\circ} 02^{\prime} \mathrm{E}$ & 农业用地 \\
\hline 涪陵区白涛 & 乌江 & $29^{\circ} 32^{\prime} \mathrm{N}, 107^{\circ} 29^{\prime} \mathrm{E}$ & 河滩地 \\
\hline 长寿区但渡 ～～～～～～～ & 龙溪河 & $29^{\circ} 49^{\prime} \mathrm{N}, 107^{\circ} 07^{\prime} \mathrm{E}$ & 农业用地 \\
\hline 南岸区广阳坝支流古河道 & 广阳坝古河道 & $29^{\circ} 33^{\prime} \mathrm{N}, 106^{\circ} 41^{\prime} \mathrm{E}$ & 河滩地 \\
\hline
\end{tabular}

样品经冷冻干燥器低温冷冻干燥处理后, 碾磨过 100 目笁, 处理后装人聚乙烯密封袋中, 并存储于 $-20^{\circ} \mathrm{C}$ 冰箱中以备化学分析. 土壤有机质 $(\mathrm{OM})$ 采用重铬酸钾-外加热法进行测定, TN 采用凯氏法进行测定.

\section{2 结果与讨论}

\section{$2.1 \mathrm{OM}$ 在消落带土壤中的含量分布特征}

消落带有机物输人输出量的相对大小 决定其土壤中有机质含量的变化. 土壤中的 有机质输人主要依赖于有机残体归还量的 多少及有机残体的腐殖化系数, 有机质的输 出量则主要包括分解和侵蚀损失, 受各种生 物和非生物条件的控制 ${ }^{[15-17]}$. 除此之外, 消 落带的干湿交替 ${ }^{[18]}$ 、管理方式及污染物质的 输人也同样影响着消落带土壤中有机质含 量的分布.

OM 在研究区域内的含量统计分析结果 表明, 消落带土壤 $\mathrm{OM}$ 含量平均值为 $10.70 \pm$ $4.03 \mathrm{mg} / \mathrm{g}$, 与对照带土壤 $\mathrm{OM}$ 含量相比, 二 者差异性不显著 ( sig. >0.05), 但对照带样 品的变异系数为 $57.7 \%$, 高于消落带样品
表 2 研究区域消落带 $\mathrm{OM} 、 \mathrm{TN}$ 和 $\mathrm{C} / \mathrm{N}$ 的统计分析*

Tab. 2 Statistical analysis of $\mathrm{OM}, \mathrm{TN}$ and $\mathrm{C} / \mathrm{N}$ ratio in the soils of study area

\begin{tabular}{cccccc}
\hline $\begin{array}{c}\text { 分析 } \\
\text { 项目 }\end{array}$ & 采样区域 & 变化范围 & 平均值 & 标准差 & $\begin{array}{c}\text { 变异系数 } \\
/ \%\end{array}$ \\
\hline $\mathrm{OM}$ & 对照样 & $1.80 \sim 23.09$ & 10.32 & 5.95 & 57.7 \\
& 消落带样 & $3.89 \sim 18.14$ & 10.70 & 4.03 & 37.7 \\
$\mathrm{TN}$ & 对照样 & $0.23 \sim 2.97$ & 1.10 & 0.87 & 79.1 \\
& 消落带样 & $0.26 \sim 1.90$ & 0.84 & 0.39 & 46.7 \\
$\mathrm{C} / \mathrm{N}$ & 对照样 & $2.53 \sim 12.75$ & 6.12 & 2.51 & 41.0 \\
& 消落带样 & $4.04 \sim 22.47$ & 8.32 & 3.86 & 46.4 \\
\hline
\end{tabular}

* $\mathrm{OM}$ 和 $\mathrm{TN}$ 的变化范围、平均值和标准差的单位均为 $\mathrm{mg} / \mathrm{g}$, $\mathrm{C} / \mathrm{N}$ 没有单位; 对照样 $(n=13)$, 消落带样 $(n=41)$. 
表 3 不同区域类型 $\mathrm{OM}$ 和 $\mathrm{TN}$ 含量比较

Tab. 3 Comparison of OM and TN contents in different areas

\begin{tabular}{lccc}
\hline 研究区域 & 区域类型 & $\mathrm{OM} /(\mathrm{mg} / \mathrm{g})$ & $\mathrm{TN} /(\mathrm{mg} / \mathrm{g})$ \\
\hline 三峡水库重庆段本研究 & 消落带 & $3.89 \sim 18.14$ & $0.26 \sim 1.90$ \\
三峡水库大宁河 $^{[9]}$ & 消落带 & - & $1.25 \sim 2.44$ \\
三峡水库澎溪河 & 消落带 & $7.10 \sim 34.50^{[19]}$ & $0.46 \sim 2.14{ }^{[20]}$ \\
梁子湖 $^{[21]}$ & 湿地 & $18.30 \sim 64.70$ & $1.15 \sim 3.41$ \\
升金湖 $^{[22]}$ & 湿地 & $23.60 \sim 31.34$ & $1.10 \sim 2.86$ \\
三江平原 $^{[23]}$ & 湿地 & $165.50 \sim 317.22$ & $7.4 \sim 17.6$ \\
太湖五里湖 $^{[24]}$ & 沉积物 & $48.96 \sim 69.48$ & $1.70 \sim 4.90$ \\
巢湖 $^{[24]}$ & 沉积物 & $7.41 \sim 27.24$ & $0.70 \sim 1.90$ \\
龙感湖 $^{[24]}$ & 沉积物 & $16.55 \sim 35.69$ & $1.30 \sim 3.30$ \\
\hline “” & & &
\end{tabular}

“一”表示数据缺失.
分布直方图见图 2a. 正态性检验显示消落带土 壤样品 OM 含量服从正态分布, 表明其分布 比较集中. 研究区域内, 消落带 $O M$ 含量均值 置信度 0.95 的置信区间为 $(9.42,11.97)$, 即有 $95 \%$ 的可能性认为研究区域内消落带 土壤的 OM 含量均值落在该置信区间内.

不同研究区域 OM 含量表明,本研究区 域消落带土壤 OM 含量处于较低水平, 明显 低于澎溪河消落带、其他区域湿地和沉积物 $\mathrm{OM}$ 含量 (表 3 ). 这可能是因为张雷等 ${ }^{[19]}$ 对 澎溪河消落带采样时间为 2009 年, 早于本 研究,由于土壤在水中长时间浸泡, OM 会逐 渐分解, 导致其含量降低且分布均匀 ${ }^{[9]}$; 而

三江平原和梁子湖湿地的土壤主要是沼泽土, 含有大量的腐殖质, 因此其 OM 含量相对而言略高; 太湖五里 湖受人为活动影响较大, 富营养化程度严重, 且为湖湾, 水体动力条件较弱, 有利于 OM 和营养盐的沉积, 导 致 $\mathrm{OM}$ 含量较高; 巢湖富营养化程度相比太湖较弱, 且为浅水湖泊, 水动力条件较强, 不利于 $\mathrm{OM}$ 的积累. 而 三峡库区消落带土壤较低的 OM 含量可能与库区的水动力相对较强, 不利于 $\mathrm{OM}$ 和营养盐的积累, 以及消落 带的水土侵蚀导致土壤 $\mathrm{OM}$ 和营养元素的流失有关.
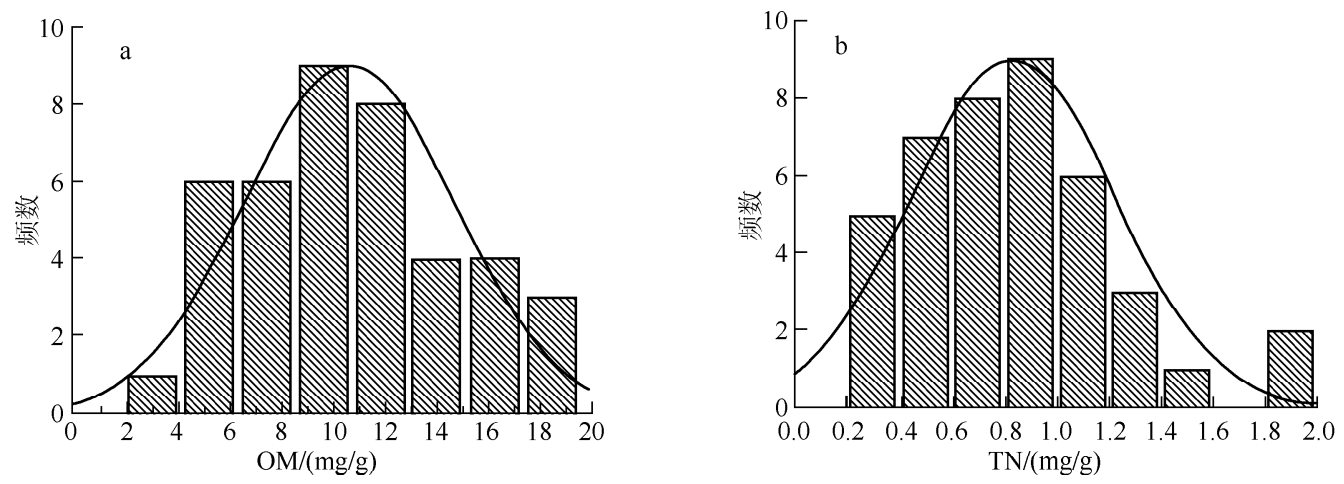

图 $2 \mathrm{OM}(\mathrm{a}) 、 \mathrm{TN}(\mathrm{b})$ 在研究区域土壤中的频数分布

Fig. 2 The distribution of frequency of $\mathrm{OM}(\mathrm{a})$ and $\mathrm{TN}(\mathrm{b})$ contents in the soils of study area

\subsection{TN 在消落带土壤中的含量分布特征}

氮素的输人和输出量的相对大小决定着土壤中全氮的含量变化. 土壤中的氮素主要来源于植物残体的 归还量及生物固氮, 也有少量来源于大气降水; 输出主要是土壤中有机质的分解, 分解后大部分被植物吸收 利用, 部分 $\mathrm{NH}_{3}$ 经过矿化 (氨化)、硝化、反硝化作用以及氨挥发等生物过程而重返大气中 ${ }^{[25-27]}$. 除此之外, 消

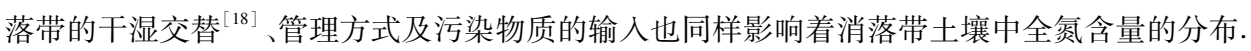

消落带土壤 TN 含量的统计分析表明, 研究区域消落带土壤样品 TN 含量的平均值为 $0.84 \pm 0.39 \mathrm{mg} / \mathrm{g}$, 与 对照带土壤 TN 含量相比, 二者差异性不显著 ( sig. >0.05), 但对照带样品的变异系数为 $79.1 \%$, 高于消落 带样品 (46.7\%), 表明消落带干湿交替可减小不同区域消落带之间土壤 TN 含量差异 (表 2 ). 消落带土壤 $\mathrm{TN}$ 含量的频数分布直方图见图 2b. 正态性检验显示消落带土壤样品 TN 含量服从正态分布, 也表明其分布 比较集中. 研究区域内, 消落带土壤 TN 含量均值置信度 0.95 的置信区间为 $(0.71,0.96)$, 即可以认为研究 区域内消落带土壤的 TN 含量均值落在该置信区间内的概率为 $95 \%$.

从不同研究区域 $\mathrm{TN}$ 含量的比较可知, 库区消落带 $\mathrm{TN}$ 含量处于较低的水平 (表 3). 其中大宁河 ${ }^{[9]}$ 和澎 
溪河 ${ }^{[20]}$ 的采样时间均早于本研究, 由于 $\mathrm{OM}$ 和 $\mathrm{TN}$ 的相关性极显著 (后文已分析), 二者有相同的输人和输 出途径, 因此 $\mathrm{OM}$ 的分解可能导致土壤中氮的释放. 其他研究区域湿地/沉积物 TN 含量的大小顺序与 $\mathrm{OM}$ 含量的大小顺序基本一致, 但龙感湖 $\mathrm{TN}$ 含量较高. 因龙感湖为典型的草型湖泊, 大型水草在固定营养盐方 面具有重要的作用, 所以其 TN 含量较高, 而其他研究区域 TN 含量高低的原因与 OM 类似.

\section{3 研究区域内消落带土壤碳氮比}

土壤碳氮比指示土壤生物分解过程中碳和氮转化作用的密切关系. 正常耕地的土壤生物在土壤 $\mathrm{C} / \mathrm{N}$ 约 为 25 时获得平衡营养. 如果 $\mathrm{C} / \mathrm{N}$ 高于 25 , 表明土壤中的 $\mathrm{N}$ 含量无法满足微生物的需要, 此时 $\mathrm{N}$ 不但不会积 累, 而且腐败菌类会迅速繁殖, 加快 $\mathrm{OM}$ 的分解, 并且土壤中的 $\mathrm{NH}_{4}^{+}-\mathrm{N}$ 含量不足以产生硝化作用 ${ }^{[28]}$. 研究区 域内消落带土壤 $\mathrm{C} / \mathrm{N}$ 相对较低, 变化范围为 $4.04 \sim 22.47$ (表 2 ), 这意味着土壤中有机碳具有较高的腐殖化 程度, 有机氮易于矿化, 致使消落带土壤无机氮的增加 ${ }^{[16]}$, 从而导致研究区域较低的 $\mathrm{C} / \mathrm{N}$, 其均值为 $8.32 \pm$ 3. 86. 相比对照带样品的 $\mathrm{C} / \mathrm{N}$, 变化范围为 $2.53 \sim 12.75$, 库区消落带土壤在经过特有的干湿交替后土壤 $\mathrm{C} / \mathrm{N}$ 有所增加, 但仍然较低, 并且 $\mathrm{OM}$ 的增加程度远远小于 $\mathrm{TN}$ 的减小程度, 由此表明消落带土壤无机氮在淹水 期间存在向上覆水体释放的可能性.

\section{4 消落带土壤基本理化特征及其与 $\mathrm{OM} 、 \mathrm{TN} 、 \mathrm{C} / \mathrm{N}$ 之间的相互关系}

研究区域内 ORP 为 $-49.90 \sim 63.90 \mathrm{mV}$, 含水率为 $16.2 \% \sim 67.9 \%, \mathrm{pH}$ 为 $5.92 \sim$ 7.76. 其中大部分采样点的 $\mathrm{pH}$ 值大于 7 , 处于中性偏微碱性的范围, 且 ORP 整体 上也呈还原性.

从研究区域土壤基本理化性质及 $\mathrm{OM} 、 \mathrm{TN} 、 \mathrm{C} / \mathrm{N}$ 之间的相关性可以看出, 消 落带土壤 $\mathrm{OM}$ 与 $\mathrm{pH}$ 值呈显著正相关, 与 ORP 呈显著负相关, 表明库区消落带土 壤 $\mathrm{pH}$ 值和 ORP 对土壤 OM 分布会造成 一定的影响 (表 4). 土壤 $\mathrm{pH}$ 值对 $\mathrm{OM}$ 的 影响常常通过影响土壤微生物的活动来 实现 ${ }^{[29]}$. 在中性条件下微生物活性最

表 4 消落带土壤理化指标及 $\mathrm{OM} 、 \mathrm{TN}$ 之间的相关系数矩阵

Tab. 4 Matrix of correlation coefficients between OM,

$\mathrm{TN}$ and physical and chemical indexes

\begin{tabular}{ccccccc}
\hline 相关因子 & ORP & 含水率 & $\mathrm{pH}$ & $\mathrm{OM}$ & $\mathrm{TN}$ & $\mathrm{C} / \mathrm{N}$ \\
\hline ORP & 1.000 & & & & & \\
含水率 & -0.159 & 1.000 & & & & \\
$\mathrm{pH}$ & $-0.993^{* *}$ & 0.151 & 1.000 & & & \\
$\mathrm{OM}$ & $-0.327^{*}$ & 0.268 & $0.339^{*}$ & 1.000 & & \\
$\mathrm{TN}$ & -0.218 & 0.093 & 0.240 & $0.674^{* *}$ & 1.000 & \\
$\mathrm{C} / \mathrm{N}$ & -0.017 & 0.039 & 0.008 & 0.143 & $-0.513^{* *}$ & 1.000
\end{tabular}

*表示在 0.05 水平上显著相关, $* *$ 表示 0.01 水平上显著相关; 样 本数 $n=41$.

强, 在强碱和强酸条件下其活动受到抑制, 从而抑制有机质的分解转化. 而研究区域内消落带土壤 $\mathrm{pH}$ 值整 体上偏微碱性, 这可能是导致 $\mathrm{pH}$ 值对该区域消落带 $\mathrm{OM}$ 分布产生一定影响的原因. 土壤 ORP 的高低表征了 其氧化性和还原性, 相对于还原条件来说, 土壤 OM 在氧化条件下更易被氧化分解, 所以在 ORP 高时, 土壤 $\mathrm{OM}$ 含量相对较低, 反之则相对较高.

研究区域内土壤 $\mathrm{OM}$ 与 $\mathrm{TN}$ 呈极显著正相关, 相关系数 $r=0.674$, 表明 $\mathrm{TN}$ 和 $\mathrm{OM}$ 具有相同的消长趋势 (表 4), 这同以往的研究结果相一致 ${ }^{[29-30]}$. 此外, OM 和 TN 呈极显著正相关也表明研究区域内有机氮可能为 消落带土壤氮形态主要存在形式之一, 在对氮形态的分析中发现有机氮在消落带土壤氮形态中占有较高的 比重, 为氮素的主要存在形态 (另文发表). $\mathrm{C} / \mathrm{N}$ 与 $\mathrm{OM}$ 之间的相关性不显著, 而 $\mathrm{C} / \mathrm{N}$ 与 $\mathrm{TN}$ 呈极显著负相 关, 其相关系数 $r=-0.513$, 由此表明 $\mathrm{C} / \mathrm{N}$ 的变化主要由 $\mathrm{TN}$ 含量决定, 该结果与白军红等 ${ }^{[16]}$ 对内蒙古乌兰 泡湿地的研究结果一致.

\section{3 结论}

1) 研究区域消落带 OM 和 TN 含量均服从正态分布, 且其在消落带样品中的变异系数均低于对照带样 品, 表明消落带干湿交替是影响消落带土壤 OM 和 TN 分布的重要因子. 与其它区域土壤 OM 和 TN 含量的 比较表明, 库区消落带土壤 OM 和 TN 含量处于偏低水平, 且与消落带的早期研究成果对比后发现, 消落带 土壤 $\mathrm{OM}$ 和 TN 含量随三峡水库运行时段而有所降低.

2) 库区消落带土壤 $\mathrm{C} / \mathrm{N}$ 介于 $4.04 \sim 22.47$ 之间, 相比对照带的 $\mathrm{C} / \mathrm{N}$ 较低, 表明消落带土壤有机氮容易 
发生分解矿化生成无机氮, 增加其在淹水过程中向上覆水体释放的潜力.

3) 土壤 TN 与 OM 呈极显著正相关, 表明消落带土壤 TN 和 OM 具有相同的消长趋势; C/N 与 TN 呈极 显著负相关,而与 $\mathrm{OM}$ 相关性不显著, 表明 $\mathrm{C} / \mathrm{N}$ 的大小主要取决于 $\mathrm{TN}$ 含量; 土壤 $\mathrm{pH} 、 \mathrm{ORP}$ 与 $\mathrm{OM}$ 的相关性 表明 $\mathrm{pH} 、 \mathrm{ORP}$ 是影响 $\mathrm{OM}$ 分布的重要因子. 对于消落带土壤的迁移转化机制以及截留和释放尚待进一步定 量研究.

\section{4 参考文献}

[ 1 ] Wantzen KM, Rothhaupt KO, Cantonati M et al. Ecological effects of water-level fluctuations in lakes: an urgent issue. Hydrobiologia, 2008, 613 (1) : $1-4$.

[2] 谢德体, 范小华. 三峡库区消落带生态系统演变与调控. 北京:科学出版社, 2010: 1-3.

[3] 王学雷, 蔡述明, 任宪友等. 三峡库区湿地生态建设与保护利用. 长江流域资源与环境, 2004, 13(2):149-152.

[ 4 ] Mitsch WJ, Gosselink JG. Wetlands. New York: Van Nostrand Reinhold Company Inc. , 2000: 89-125.

[ 5 ] Franzluebbers AJ. Soil organic matter stratification ratio as an indicator of soil quality. Soil \& Tillage Research, 2002,66 (2) : 95-106.

[ 6 ] Bilen S, Çelik A, Altlkat S. Effects of strip and full-width tillage on soil carbon IV oxide-carbon( $\left.\mathrm{CO}_{2}-\mathrm{C}\right)$ fluxes and on bacterial and fungal populations in sunflower. African Journal of Biotechnology, 2010, 9(38): 6312-6319.

[7] 白军红, 邓 伟, 朱颜明等. 水陆交错带土壤氮素空间分异规律研究——以亮泡水陆交错带为例. 环境科学学 报, 2002, 22(3):343-348.

[8] 喻 菲, 张 成, 张 暏等. 三峡水库消落区土壤重金属含量及分布特征. 西南农业大学学报: 自然科学版, $2006,28(1): 165-168$.

[9] 张 雷, 秦延文, 郑丙辉等. 三峡人库河流大宁河回水区浸没土壤及消落带土壤氮形态及分布特征. 环境科学, $2009,30(10):$ 2884-2890.

[10] 徐德星, 秦延文, 张 雷等. 三峡人库河流大宁河回水区沉积物和消落带土壤磷形态及其分布特征研究. 环境科 学, 2009, 30(5): 1338-1343.

[11] 吉芳英, 曹 琳, 林 茂等. 三峡库区新生消落区沉积物磷形态分析. 环境科学研究, 2009, 22(8):882-886.

[12] 詹艳慧, 王里奥, 焦艳静. 三峡库区消落带土壤氮素吸附释放规律. 重庆大学学报: 自然科学版, 2006, 29(8): $10-13$.

[13] 胡 刚, 王里奥, 袁 辉等. 三峡库区消落带下部区域土壤氮磷释放规律模拟实验研究. 长江流域资源与环境, 2008,17 ( 5 ) : 780-784.

[14] 唐 将, 李 勇, 邓富银等. 三峡库区土壤营养元素分布特征研究. 土壤学报, 2005, 42(3):473-478.

[15] Brown S, Lenart M, Mo JM et al. Structure and organic matter dynamics of a human-impacted pine forest in a MAB reserve of subtropical China. Biotropica, 1995, $27(3): 276-289$.

[16] 白军红, 邓 伟, 张玉霞. 内蒙古乌兰泡湿地环带状植被区土壤有机质及全氮空间分异规律. 湖泊科学, 2002, 14(2) : 145-151.

[17] Wang L, Ouyang H, Peng K et al. Distribution characteristics of SOM and nitrogen on the eastern slope of Gongga Mountain. Journal of Geographical Sciences, 2004, 14(4) : 481-487.

[18] Fromin N, Pinay G, Montuelle B et al. Impact of seasonal sediment desiccation and rewetting on microbial processes involved in greenhouse gas emissions. Ecohydrol, 2010, 3: 339-348.

[19] 张 雷, 秦延文, 贾 静等. 三峡人库河流澎溪河回水区消落带与岸边土壤磷形态及其分布特征研究. 环境科学 学报, $2011,31(9)$ : 1999-2007.

[20] 郭劲松, 贺 阳, 付 川等. 三峡库区腹心地带消落区土壤氮磷含量调查. 长江流域资源与环境, 2010, 19 (3): 311-317.

[21] 熊汉锋, 王运华. 梁子湖湿地土壤养分的空间异质性. 植物营养与肥料学报, 2005, 11(5): 584-589.

[22] 迟传德, 许信旺, 吴新民等. 安徽省升金湖湿地土壤有机碳储存及分布. 地球与环境, 2006, 34(3): 59-64.

[23] 石福臣, 李瑞利, 王绍强等. 三江平原典型湿地土壤剖面有机碳及全氮分布与积累特征. 应用生态学报, 2007, 18 ( 7 ) : 1425-1431.

[24] 李 军. 长江中下游地区浅水湖泊生源要素的生物地球化学循环 [学位论文]. 贵州: 中国科学院地球化学研究 
所, 2005.

[25] Delaune RD, Lindau CW, Sulaeman E et al. Nitrification and denitrification estimates in a Louisana Swamp forest soil as assessed by ${ }^{15} \mathrm{~N}$ isotope dilution and direct gaseous measurements. Water Air and Soil Pollution, 1998, 106 (1/2): 150-161.

[26] Chen R, Twilley R. A simulation model of organic matter and nutrient accumulation in mangrove wetland soils. Biogeochemistry, 1999, 44(1): 93-118.

[27] Arce MI, Gómez R, Vidal-Abarca MR et al. Effects of Phragmites australis growth on nitrogen retention in a temporal stream. Limnetica, 2009, 28(2) : 229-242.

[28] 吕国红, 周 莉, 赵先丽等. 芦苇湿地土壤有机碳和全氮含量的垂直分布特征. 应用生态学报, 2006, 17 (3): 384-389.

[29] 白军红, 邓 伟, 张玉霞等. 洪泛区天然湿地土壤有机质及氮素空间分布特征. 环境科学, 2002, 23(2):77-81.

[30] 石福臣, 李瑞利, 王绍强等. 三江平原典型湿地土壤剖面有机碳及全氮分布与积累特征. 应用生态学报, 2007, 18(7) : 1425-1431. 